\title{
Assessing depression and anxiety in the caregivers of pediatric patients with chronic skin disorders
}

\author{
Avaliação da depressão e ansiedade em cuidadores de pacientes pediátricos \\ com dermatoses crônicas
}

\author{
Ana Paula Dornelles da Silva Manzoni ${ }^{1}$ \\ Aline Rodrigues da Silva Nagatomi ${ }^{3}$ \\ Roberta Zaffari Townsend ${ }^{3}$
}

\author{
Magda Blessmann Weber ${ }^{2}$ \\ Rita Langie Pereira ${ }^{3}$ \\ Tania Ferreira Cestari ${ }^{4}$
}

DOI: http://dx.doi.org/10.1590/abd1806-4841.20131915

\begin{abstract}
BACKGROUND: The literature has shown that the presence of emotional disturbances in caregivers of children with skin diseases affects the course and treatment of the disease. Anxiety and depression are among the most frequently reported psychiatric diagnoses related to this fact. OвJECTIVE: To evaluate the presence of anxiety and depression in caregivers of pediatric patients with chronic skin disorders, exemplified by atopic dermatitis, psoriasis and vitiligo, and correlate them to the quality of life of the patients. METHODS: The sample consisted of 118 patients with atopic dermatitis, vitiligo and psoriasis, monitored by their main caregiver. The levels of anxiety and depression in the caregivers were assessed using the Hamilton Anxiety Scale and the Beck Depression Inventory, respectively. The Children's Dermatology Life Quality Index was applied. REsults: Anxiety was observed in $36 \%$ of the caregivers of the patients with atopic dermatitis, in 36\% of those of children affected by psoriasis, and in $42 \%$ of those responsible for pediatric patients with vitiligo. Depression occurred in $36 \%$ of the caregivers of patients with atopic dermatitis, in $36 \%$ of those of children affected by psoriasis and in $26 \%$ of those responsible for pediatric patients with vitiligo. There was a significant correlation between poor quality of life scores in patients with vitiligo and the presence of depression and anxiety in their caregivers. ConCLUSION: Emotional disorders tend to be present among close family members of children with the chronic skin diseases studied and their prevention can help in controlling and treating these diseases.
\end{abstract}

Keywords: Anxiety; Depression; Dermatitis, atopic; Psoriasis; Vitiligo

Resumo: FunDAMENTOS: A literatura tem demonstrado que a presença de distúrbios emocionais nos cuidadores de crianças com dermatoses influenciam no curso e tratamento da doença. A ansiedade e a depressão estão entre os diagnósticos psiquiátricos descritos, porém a maioria das publicações afere esta relação de forma indireta e não de escalas diretas para ansiedade e depressão. OBJETIVO: Avaliar a presença de ansiedade e depressão nos cuidadores de pacientes pediátricos com dermatite atópica, vitiligo e psoríase e correlacioná-las à qualidade de vida dos pacientes. MATERIAIS E MÉTODOs: Amostra composta por 118 pacientes com dermatite atópica, vitiligo e psoríase acompanhados pelo principal responsável por seus cuidados diários. A avaliação da ansiedade nos cuidadores foi realizada através da Escala de Hamilton de Ansiedade e a depressão através do Inventário de Beck para Depressão. Foi aplicado o Índice de Qualidade de Vida na Dermatologia Infantil. Resultados: Ansiedade foi verificada em $36 \%$ dos cuidadores do grupo de pacientes com dermatite atópica, em $36 \%$ do grupo com psoríase e $42 \%$ do grupo com vitiligo. Depressão ocorreu em $36 \%$ dos cuidadores de pacientes com dermatite atópica, $36 \%$ dos responsáveis pelos pacientes com psoríase, e em $26 \%$ dos cuidadores de pacientes com vitiligo. Observou-se uma correlação significativa entre a pior qualidade de vida dos pacientes com vitiligo e a presença de depressão e ansiedade nos seus cuidadores. ConcLusão: Distúrbios emocionais tendem a estar presentes no nicho familiar de crianças portadoras das dermatoses crônicas estudadas, e que a prevenção pode auxiliar no controle e no tratamento destas doenças.

Palavras-chave: Ansiedade; Depressão; Dermatite atópica; Psoríase; Vitiligo

Received on 07.06.2012.

Approved by the Advisory Board and accepted for publication on 08.01.2013.

* Work performed at the Serviço de Dermatologia da Universidade Federal de Ciências da Saúde de Porto Alegre (UFCSPA) - Centro de Saúde Santa Marta, Serviço de Dermatologia da Universidade Federal do Rio Grande do Sul (UFRGS) - Hospital de Clínicas de Porto Alegre e Ambulatório de Dermatologia da Universidade Luterana do Brasil (ULBRA) - Canoas (RS), Brazil.

Financial Support: FIPE

Conflict of Interest: None.

PhD Universidade Federal do Rio Grande do Sul (UFRGS) - Collaborating Professor at the Universidade Federal de Ciencias da Saude de Porto Alegre (UFCSPA) Porto Alegre (RS), Brazil.

PhD Universidade Federal do Rio Grande do Sul (UFRGS) - Assistant Professor of the Universidade Federal de Ciencias da Saude de Porto Alegre (UFCSPA) - Porto Alegre (RS), Brazil.

Physician at a Private Clinic - Porto Alegre (RS), Brazil.

PhD Universidade Federal do Rio de Janeiro (UFRJ) - Associate Professor at the Universidade Federal do Rio Grande do Sul (UFRGS) - Porto Alegre (RS), Brazil.

(C)2013 by Anais Brasileiros de Dermatologia 


\section{INTRODUCTION}

Many authors have referred to the close relationship between the skin and the psyche. This association has been shown to be important, from the formation of the ego to the understanding of the skin as a means of communication with the outside world. ${ }^{1}$ Based on this evidence, the literature has demonstrated the influence of psychological issues in the treatment of certain skin diseases and the necessity of understanding these mechanisms in order to obtain better treatment results. ${ }^{2,3,4}$

In the context of pediatric dermatology, one must pay attention to the intense emotional and biological connection between children and their caregivers and the degree to which this relationship regulates and influences children's behavior. ${ }^{1,4}$ The skin has an important role in this connection because it is through the skin that the child perceives its first sensations and begins to identify what is pleasurable or not. ${ }^{1,4}$ Thus, the presence of skin disease can have repercussions on the children-adult bond and the healthy development of a relationship., ${ }^{1,2}$

It is estimated that there is some psychosomatic influence on the genesis of the disease in one third of patients with dermatoses. ${ }^{1}$ Therefore, it is important to assess the difficulties faced by patients and their ability to provide healthy adaptive responses toward the disease. In the pediatric population, some authors suggest that the early onset of skin diseases is seldom related to a psychic trigger event. ${ }^{1,5}$ However, other studies have shown that children are susceptible to imbalances in their homes, contributing to psychosomatization even at an early age. ${ }^{1,4,6}$

It has been reported that deprivation or stress in early childhood causes alterations in brain structure and neuroendocrine secretions. ${ }^{7}$ Furthermore, studies on pediatric populations have demonstrated the influence of stress factors in obtaining good treatment results, and pointed to the need for cognitive-behavioral monitoring for both children and their families. ${ }^{2,3,45}$ Skin diseases have a clear negative impact on family life and caregivers tend to feel overwhelmed, present sleep disturbances, fear of the future, in addition to having higher rates of absence from work and job abandonment, in order to attend to sick children. ${ }^{2,3}$ The literature also identifies the influence of the caregiver's behavioral disturbances on the child's illness, the evolution of the disease and even on the development of future adults who could be socially ill-adapted. .,8,9 $^{-1}$

Anxiety and depression in caregivers are among the psychiatric diagnoses that most affect pediatric dermatoses..$^{10-15}$ Yet, the majority of publications attempt to gauge this relationship indirectly, mainly by using scales that assess quality of life. ${ }^{11,14}$ Thus, this study aims to assess directly the levels of anxiety and depression in caregivers of pediatric patients with atopic dermatitis, vitiligo and psoriasis, which are considered the main chronic skin diseases in this age group. Additionally, we intend to investigate the correlation between caregivers' emotional symptoms and the patients' quality of life and the extent of the body area affected by the disease.

\section{MATERIALS AND METHODS \\ Sample}

A tranversal and observational study with patients with atopic dermatitis $(\mathrm{AD})$, vitiligo $(\mathrm{Vi})$ and psoriasis (Ps), diagnosed according to the classical clinical criteria for these dermatoses, or histopathological confirmation in the case of diagnostic uncertainty., ${ }^{4,16-18}$ Each selected patient was accompanied by his/her respective main caregiver in accordance with the definition from Balkrishman et al. ${ }^{19}$ Patients aged 5 to 16 were suitable for the application of the Children's Dermatology Life Quality Index (CDLQI). ${ }^{20,21}$ The exclusion criteria for patients were: diagnosis within the last 6 months, the presence of other chronic diseases under treatment and the use of neuropsychiatric medications. The exclusion criteria for caregivers were: the presence of chronic diseases and the use of neuropsychiatric medications.

Data collection was conducted between June 2009 and December 2010.

\section{Sample Calculation}

This served to estimate the frequency of patients with values below the cutoff value of $50 \%$, considering the confidence interval of $95 \%$ and a margin of error of $15 \%$. The sample makes it possible to detect a difference of 30 percentage points between the illnesses (alpha $=0.05$ and statistical power of $80 \%$ ).

\section{Survey Methodology}

The demographic information and illness duration of all patients were noted. A complete dermatological examination was performed by outlining the total affected body surface and visible, exposed areas (face, neck, forearms, and hands). The percentage of the affected body surface was calculated according to the human model for burns patients. ${ }^{20}$

Quality of Life (QoL) was assessed using the Children's Dermatology Life Quality Index (CDLQI) questionnaire, which has been validated for Brazilian Portuguese. ${ }^{21}$ This instrument is made up of 10 questions to be answered by patients aged between 5 and 16 , taking into account 6 domains - symptoms and feelings, leisure, school or holidays, personal relationships, sleep and treatment. Each question is scored as follows: 
"very much" = 3, "a lot" = scored 2; "a little" = 1 and "not at all" $=0$. The total score ranges from 0 to 30 , with values of 0 and 1 indicating no effect on the child's life, 2-6 a weak effect, 7 to 12 a moderate effect, 13 to 18 a very strong and 19 to 30 extremely strong effect. ${ }^{21}$

Anxiety: The caregivers' levels of anxiety were measured using the Hamilton Anxiety Scale (HAS). This instrument consists of 14 items that address aspects of psychic and somatic anxiety. Each item is rated on a 5-point scale, ranging from 0 (not present) to 4 (severe). The level varies according to the sum of the scores, where up to 17 indicates absence of or mild, anxiety, 18 to 24 mild to moderate anxiety and, 25 to 30, moderate to severe. Scores of over than 17 were considered indicative of anxiety. ${ }^{22,23}$

Depression: The Beck Depression Inventory (BDI) was used to assess caregivers levels of depression. This instrument comprises 21 items that consider cognitive aspects of depression. Each item is rated on a 4-point scale, ranging from 0 (minimal) to 3 (severe). The level varies according to the sum of the scores, where up to 9 indicates absence of depression, 10-18 mild, 19 to 29 moderate and, 30 to 63 , severe depression. Scores of over 10 were considered indicative of depression. ${ }^{24}$

\section{Statistical Analysis and Ethical Considerations}

Categorical variables were described by the absolute frequency and percentage of relative frequen$\mathrm{cy}$, while quantitative variables were described by mean and standard deviation when variables had symmetric distribution, and by the median and interquartile range when the distribution was asymmetric. Categorical variables were compared using the chi-square test, while quantitative variables were compared using ANOVA and Tukey's tests for multiple comparisons. Quantitative variables with asymmetrical distribution were analyzed by means of the Kruskal-Wallis test and variable position transformation was performed in order to use the Tukey's test for multiple comparisons. The Spearman's correlation coefficient was used to associate quantitative variables.

The project and all its procedures were submitted to and approved by the Institutional Review Board. All patients and their caregivers were fully informed about the nature of the study and gave their written consent.

\section{RESULTS}

Of the total of 118 patients analyzed, 50 had atopic dermatitis, 43 had vitiligo, and 25 had psoriasis. The psoriasis group was significantly smaller due to the lower prevalence of the disease in this age group when compared with the other two groups. All patients were accompanied by their primary care- givers: the mother (78\% of cases), father $(9.5 \%)$, grandparents $(8.5 \%)$, sister $(1 \%)$ and stepfather $(1 \%)$.

Anxiety was present in $36 \%$ of caregivers in the group of patients with atopic dermatitis, in 36\% of those responsible for patients with psoriasis and in $42 \%$ of those responsible for patients with vitiligo. Similarly, depression was observed in $36 \%$ of the caregivers of atopic dermatitis patients, $36 \%$ of those responsible for patients with psoriasis and $26 \%$ of caregivers of patients with vitiligo.

An analysis of depression and anxiety symptoms among the caregivers of patients with the three types of dermatoses revealed a statistically significant correlation between the worse quality of life of vitiligo patients and the presence of both depression and anxiety in their caregivers. This significance was not observed in the groups with atopic dermatitis and psoriasis (Table 1).

The assessment of the total body surface affected by dermatosis and the presence of emotional symptoms in caregivers demonstrated a statistically significant correlation between the total extent of the disease and the presence of depression and anxiety in the caregivers of patients with psoriasis. The other dermatoses examined did not show such a correlation (Table 1). However, a similar analysis of the visible body surface area demonstrated a significant correlation with the presence of anxiety in the caregivers of vitiligo patients (Table 1 ).

The quality of life analysis showed statistically significant differences, with worse QoL scores in the groups of patients with atopic dermatitis and psoriasis, compared with those with vitiligo. However, it was not possible to demonstrate significant correlations between the QoL indexes and the rates of depression and anxiety among the caregivers of patients in the sample studied (Table 2).

\section{DISCUSSION}

Caring for children affected by chronic skin diseases is a task that requires a significant degree of family involvement. However, we still lack a full understanding of what particular psychosocial problems are experienced and their impact on childhood illness. ${ }^{4,8,25,26}$ In studies on the quality of life of relatives of patients with chronic skin diseases, the presence of anxiety and depression are often mentioned. ${ }^{48,9,26}$ However, these reports do not assess directly their frequency and impact on pediatric chronic dermatoses.

In the present study, higher percentages of anxiety and depression were observed in caregivers of the three disease groups (DA $36 \%$ Vi $42 \%$ and $36 \%$ for anxiety Ps; DA 36\% Vi 26\% and 36\% for depression Ps) when compared with data on the general population 
TABLE 1: Comparison of the quality of life of patients with chronic skin diseases and total body surface exposed and affected by the disease in relation to the presence or absence of depression in their caregivers

\begin{tabular}{|c|c|c|c|c|}
\hline & & \multicolumn{3}{|c|}{ CHRONIC SKIN DISEASES } \\
\hline & & Atopic Dermatitis & Vitiligo & Psoriasis \\
\hline & & \multicolumn{3}{|c|}{ QUALITY OF LIFE OF THE PATIENTS* - Median (P25 - P75) } \\
\hline \multirow{3}{*}{$\begin{array}{l}\text { Depression in the } \\
\text { caregivers** }\end{array}$} & Absent & $8.5(5-12.5)$ & $2(1-4.5)$ & $5(2.25-12.25)$ \\
\hline & Present & $9(4.75-14.25)$ & $4(1.75-8.5)$ & $8(4.5-16.5)$ \\
\hline & $\mathbf{p}$ & 0.453 & 0.032 & 0.419 \\
\hline \multirow{4}{*}{$\begin{array}{l}\text { Anxiety in the } \\
\text { caregivers*** }\end{array}$} & Absent & $8(5-11)$ & $2(1-4)$ & $5.5(2.25-12.5)$ \\
\hline & Present & $10(6.25-14.75)$ & $7(2-12)$ & $8(4-16.5)$ \\
\hline & $\mathbf{p}$ & 0.134 & 0.001 & 0.452 \\
\hline & & \multicolumn{3}{|c|}{ TOTAL EXTENSION OF THE DISEASE - MEDIAN (P25 - P75) } \\
\hline \multirow{3}{*}{$\begin{array}{l}\text { Depression in the } \\
\text { caregivers** }\end{array}$} & Absent & $9.5(6.25-27)$ & $4(2-8)$ & $3.5(2-19.5)$ \\
\hline & Present & $9.5(5.75-24.25)$ & $3.5(1.75-11)$ & $36(5.5-70.5)$ \\
\hline & p & 0.613 & 0.756 & 0.027 \\
\hline \multirow{4}{*}{$\begin{array}{l}\text { Anxiety in the } \\
\text { caregivers*** }\end{array}$} & Absent & $10.5(6.25-23.75)$ & $3.5(2-7.5)$ & $3.5(2-7.5)$ \\
\hline & Present & $9(5-27)$ & $5(2-10)$ & $38(18.5-70.5)$ \\
\hline & $\mathbf{p}$ & 0.777 & 0.592 & 0.004 \\
\hline & & \multicolumn{3}{|c|}{ EXTENSION OF THE DISEASE IN EXPOSED AREAS - MEDIAN (P25 - P75) } \\
\hline \multirow{3}{*}{$\begin{array}{l}\text { Depression in the } \\
\text { caregivers }^{* *}\end{array}$} & Absent & $3(1-6.5)$ & $0(0-1.5)$ & $2.5(1-6.75)$ \\
\hline & Present & $3.5(0-6.25)$ & $1.5(0-3.25)$ & $6(3-6.5)$ \\
\hline & p & 0.992 & 0.084 & 0.251 \\
\hline \multirow{3}{*}{$\begin{array}{l}\text { Anxiety in the } \\
\text { caregivers*** }\end{array}$} & Absent & $2.5(0-5.5)$ & $0(0-1.75)$ & $2.5(1-5.5)$ \\
\hline & Present & $4.5(1-7.5)$ & $2(0-4)$ & $6(3-13)$ \\
\hline & $\mathbf{p}$ & 0.111 & 0.037 & 0.057 \\
\hline
\end{tabular}

$(10-15 \%$ for anxiety and depression to 5$10 \%) .{ }^{27}$ Possible explanations for this finding are difficult to interpret, yet the results of this study suggest that the pediatric dermatoses studied may have influenced the higher rates of anxiety and depression in caregivers. This may be due to the parents lacking in adequate adaptive mechanisms when faced with their child's disease, as the child's physical appearance may not conform to the parents' or family's idealized image. ${ }^{15}$ Thus, the patient's improvement may be compromised both by poor adherence to treatment, which is the responsibility of the caregiver, and the psychosomatization of the child who experiences the psychological distress of their caregivers. ${ }^{26,28}$
Studies have shown that one of the difficulties encountered within the family environment of a child with chronic skin disease is that the mother-child relationship tends to resemble more closely that of caregiver and patient. ${ }^{4}$ This is due to the level of demand required to ensure that all the necessary preventive and therapeutic procedures are performed. ${ }^{4}$ Caring for a child with skin disease may be more stressful than caring for patients with apparently more serious diseases such as diabetes mellitus. ${ }^{29}$

Upon analyzing the quality of life of patients and the presence of anxiety and depression in caregivers, there was a statistically significant relationship between the decrease in QoL of patients with vitiligo 
TABLE 2: Comparison of the presence of anxiety and depression in the caregivers and quality of life of pediatric patients with chronic skin diseases

\begin{tabular}{|c|c|c|c|c|c|c|}
\hline \multirow[b]{3}{*}{$\begin{array}{l}\text { SCORES OF THE } \\
\text { EVALUATED SCALE }\end{array}$} & \multicolumn{6}{|c|}{ GROUPS OF SKIN DISEASES } \\
\hline & \multicolumn{2}{|c|}{ Atopic Dermatitis } & \multicolumn{2}{|l|}{ Vitiligo } & \multicolumn{2}{|l|}{ Psoriasis } \\
\hline & $\begin{array}{l}\text { MEDIAN } \\
\text { (P25-P75) }\end{array}$ & Rank average & $\begin{array}{l}\text { MEDIAN } \\
(\mathrm{P} 25-\mathrm{P} 75)\end{array}$ & Rank average & $\begin{array}{l}\text { MEDIAN } \\
(\mathrm{P} 25-\mathrm{P} 75)\end{array}$ & Rank average \\
\hline QUALITY OF LIFE & $9(5-13)$ & $72.69^{\mathrm{A}}$ & $2(1-6)$ & $39.66^{\mathrm{B}}$ & $7(3-14.5)$ & $67.24^{\mathrm{A}}$ \\
\hline DEPRESSION & $9(4-16.5)$ & $61.34^{\mathrm{A}}$ & $6(3-17)$ & $58.36^{\mathrm{A}}$ & $9(3-14.5)$ & $57.78^{\mathrm{A}}$ \\
\hline ANXIETY & $11.5(5.8-19.3)$ & $58.61^{A}$ & $10(5-19)$ & $55.99^{\mathrm{A}}$ & $13(8.5-23.5)$ & $67.32^{\mathrm{A}}$ \\
\hline
\end{tabular}

Average ranks followed by distinct letters differ significantly, using the non-parametric Kruskal Wallis test, complemented by the multiple comparisons test, at a significance level of $5 \%$

and the presence of both anxiety and depression in their caregivers. Patients in the age group studied are characterized by emotional vulnerability. Their exposure to negative experiences related to anxiety and depression in their main caregiver can have the effect of reducing their quality of life. ${ }^{6,30}$ In turn, psychosomatic mechanisms may be linked to the worsening of skin diseases reported in pediatric studies. ${ }^{26}$ The inverse situation may also occur, where the patient's low capacity to adapt to the illness triggers anxiety and depression in caregivers who feel unable to protect their child from a stigmatized disease such as vitiligo. ${ }^{6}$ However, this study could not demonstrate the expected significant relationship between the low quality of life of patients with psoriasis and atopic dermatitis, and the presence of anxiety and depression in their caregivers. Further studies with larger samples could perhaps enrich understanding.

Caregivers of patients with psoriasis revealed a statistically significant relationship between the largest percentage of total body surface affected by the disease and the highest rate of depression and anxiety among their caregivers. This finding may be explained by the presence of feelings such as shame due to the relative limitations in leisure situations imposed by the disease and the amount of time spent performing more complex treatment. ${ }^{9,25,28}$ Another factor that may help explain these findings is the known relationship between the psychological impact of major illness on the family and the severity of disease, which can be reflected by the body area affected by it. ${ }^{1,31}$ Similarly, it should be asked to what degree psychosomatization in a patient under the care of an adult suffering from anxiety or depression can lead to worsening of the disease. ${ }^{1,31}$
An analysis of the presence of anxiety and depression among caregivers in relation to the extent of the disease in constantly exposed areas, showed there was a statistically significant relationship between caregivers of patients with vitiligo and the presence of anxiety. Published data suggests that the stigma brought about by the visibility of skin lesions is associated with mental illness and reduced quality of life in patients with vitiligo, atopic dermatitis, and psoriasis. ${ }^{1,6,7}$ Moreover, authors have described a phenomenon that links the exposure of skin diseases to a worse perception of the disease, regardless of the presence of symptoms or the total body surface affected. ${ }^{4,7}$ In the quality of life analysis of patients with exposed dermatoses, the social domain is the most affected due to the association made between skin lesions and the possibility of contagion. ${ }^{4}$ Furthermore, the influence of placing a child in a troubled environment can act as a trigger, maintainer or aggravator of the disease. ${ }^{5}$ Another fact to be emphasized is that caregivers of patients with chronic skin diseases tend to be overprotective towards the child, causing them to have higher rates of mental illnesses in adulthood. ${ }^{4}$

By comparing the three groups of dermatoses with the presence of anxiety and depression in caregivers and quality of life, we found a significant relationship between the presence of a poorer quality of life of patients with atopic dermatitis and psoriasis, compared with vitiligo patients. The literature has clearly demonstrated the impact of atopic dermatitis and psoriasis on QoL. ${ }^{25,32}$ This is due to several factors relating to negative feelings such as dissatisfaction with appearance, anxiety, depression, shame, sadness, loss of self-esteem, stigma, restricted social life and poor quality of sleep. .,14,15,33 $^{-1}$ 
Nonetheless, studies refer to a significant decrease in the QoL of patients with vitiligo, but none of them evaluate comparatively the quality of life of these three groups of dermatoses. ${ }^{1,6}$ To our knowledge, the present study is the first to demonstrate this finding. This may be due to the fact that atopic dermatitis and psoriasis are linked to the presence of symptoms such as itching, burning and pain, while vitiligo is typically asymptomatic., ${ }^{1,6}$ Thus, the discomfort caused by $\mathrm{Vi}$ is only related to aesthetic embarrassment. ${ }^{6}$

\section{CONCLUSION}

Thus, we believe that preventing and treating emotional disorders present within the close family of children with chronic skin diseases can help the therapeutic process, as well as providing a more stable life and future with fewer repercussions.

\section{REFERENCES}

1. Bick E. The experience of skin in early object relations. Int J Psychoanal. 1968;49:484-6.

2. Weber MB, Fontes Neto Pde T, Prati C, Soirefman M, Mazzotti NG, Barzenski B, et al. Improvement of pruritus and quality of life of children with atopic dermatitis and their families after joining support groups. J Eur Acad Dermatol Venereol. 2008;22:992-7.

3. Fortune DG, Richards HL, Kirby B, Bowcock S, Main CJ, Griffiths CE. A cognitive-behavioral symptom management programme as an adjunct un psoriasis therapy. $\mathrm{Br} \mathrm{J}$ Dermatol. 2002;146:458-65.

4. Carroll CL, Balkrishnan R, Feldman SR, Fleischer AB Jr, Manuel JC. The Burden of Atopic Dermatitis: Impact on the Patient, Family, and Society. Pediatr Dermatol. 2005;22:192-9.

5. Potocka A, Turczyn-Jabloñska K, Merecz D. Psychological correlates of quality of life in dermatology patients: the role of mental health and self-acceptance. Acta Dermatovenerol Alp Panonica Adriat. 2009;18:53-8, 60, 62.

6. Linthorst Homan MW, de Korte J, Grootenhuis MA, Bos JD, Sprangers MA, van der Veen JP. Impact of childhood vitiligo on adult life. Br J Dermatol. 2008;159:915-20

7. Kent G, Keohane S. Social anxiety and disfigurement: the moderating effects of fear of negative evaluation and past experience. Br J Clin Psychol. 2001;40:23-34.

8. Ricci G, Bendandi B, Aiazzi R, Patrizi A, Masi M. Three Years of Italian Experience of an Educational Program for Parents of Young Children Affected by Atopic Dermatitis: Improving Knowledge Produces Lower Anxiety Levels in Parents of Children with Atopic Dermatitis. Pediatr Dermatol. 2009;26:1-5.

9. Goh C, Lane AT, Bruckner AL. Support Groups for Children and Their Families in Pediatric Dermatology. Pediatr Dermatol. 2007;24:302-5.

10. Hayes J, Koo J. Psoriasis: depression, anxiety, smoking, and drinking habits. Dermatol Ther. 2010;23:174-80

11. Cvetkovski RS, Zachariae R, Jensen H, Olsen J, Johansen JD, Agner T. Quality of life and depression in a population of occupational hand eczema patients. Contact Dermatitis. 2006;54:106-11.

12. Hong J, Koo B, Koo J. The psychosocial and occupational impact of chronic skin disease. Dermatol Ther. 2008;21:54-9.

13. Loney T, Standage M, Lewis S. Not just 'skin deep': psychosocial effects of dermatological-related social anxiety in a sample of acne patients. J Health Psychol. 2008;13:47-54

14. Fried RG, Gupta MA, Gupta AK. Depression and skin disease. Dermatol Clin. 2005;23:657-64.

15. Picardi A, Pasquini P, Abeni D, Fassone G, Mazzotti E, Fava GA. Psychosomatic assessment of skin diseases in clinical practice. Psychother Psychosom. 2005;74:315-22.

16. Kiken DA, Silverberg NB. Atopic dermatitis in children, part 1: epidemiology, clinical features, and complications. Cutis. 2006;78:241-7.

17. Benoit S, Hamm H. Childhood psoriasis. Clin Dermatol. 2007;25:555-62.

18. Huggins RH, Schwartz RA, Janniger CK. Childhood vitiligo. Cutis. 2007;79:277-80.

19. Balkrishnan R, Housman TS, Carroll C, Feldman SR, Fleischer AB. Disease severity and associated family impact in childhood atopic dermatitis. Arch Dis Child. 2003;88:423-7.

20. Vale, ECS. Inicial management of burns: approach by dermatologists. An Bras Dermatol. 2005;80:9-19.
21. Prati C, Comparin C, Boza JC, Cestari TF. Validação para o português falado no Brasil do instrumento Escore da Qualidade de Vida na Dermatologia Infantil (CDLQI). Med Cutan Iber Lat Am. 2010;38:229-33.

22. Hamilton M. The assessment of anxiety states by rating. Br J Med Psychol. 1959;32:50-5.

23. Telles-Correia D, Barbosa A. Ansiedade e depressão em medicina - modelos teóricos e avaliação. Acta Med Port. 2009;22:89-98.

24. Gorenstein C, Andrade L. Validation of a Portuguese version of the Beck Depression Inventory and the State-Trait Anxiety Inventory in Brazilian subjects. Braz J Med Biol Res. 1996;29:453-7.

25. Eghlileb AM, Davies EE, Finlay AY. Psoriasis has a major secondary impact on lives of family members and partners. Br J Dermatol. 2007;156:1245-50

26. Schwartz R, Sepúlveda JE, Quintana T. Possible role of psychological and environmental factors in the genesis of chilhood vitiligo. Rev Med Chil. 2009;137:53-62

27. Desai NG, Isaac M. Word Health Organization. [cited 2010 Dec 6]. Available form: http://www.searo.who.int/N/Section1243/Section1310/Section1343/Section1344/Secti on1353_5279.htm.

28. Taner E, Coşar B, Burhanoğlu S, Calikoğlu E, Onder M, Arikan Z. Depression and anxiety in patients with Behçet's disease compared with that in patients with psoriasis. Int $\mathrm{J}$ Dermatol. 2007;46:1118-24.

29. Su JC, Kemp AS, Varigos GA, Nolan TM. Atopic eczema: its impact on the family and financial cost. Arch Dis Child. 1997;76:159-62.

30. Kossakowska MM, Cieścińska C, Jaszewska J, Placek WJ. Control of negative emotions and its implication for illness perception among psoriasis and vitiligo patients. J Eur Acad Dermatol Venereol. 2010;24:429-33.

31. Kotrulja L, Tadinac M, Joki-Begi NA, Gregurek R. A multivariate analysis of clinical severity, psychological distress and psychopathological traits in psoriatic patients. Acta Derm Venereol. 2010;90:251-6.

32. Basra M K A, Su-Ho R, Finlay AY. Impact of patients' psoriasis on the quality of life of their families: initial results from a validation study of a novel dermatology-specific measure. J Investig Dermatol. 2007;127:1808.

33. Magin P, Adams J, Heading G, Pond D, Smith W. The psychological sequelae of psoriasis: results of a qualitative study. Psychol Health Med. 2009;14:150-61.
MAILING ADDRESS:
Ana Paula Dornelles da Silva Manzoni
Av. Carlos Gomes, 1998/405 - Três Figueiras
90480-002 - Porto Alegre - RS
Brasil
E-mail: anamanzoni@terra.com.br

How to cite this article: Manzoni APDS, Weber MB, Nagatomi ARS, Pereira RL, Townsend RZ, Cestari TF. Assessing depression and anxiety in the caregivers of pediatric patients with chronic skin disorders. An Bras Dermatol. 2013;88(6)894-9. 